\title{
O modo de vida dos hobbits no legendário de Tolkien
}

Hobbits' way of life in the legendary of Tolkien

\section{Charles Albuquerque Ponter}

\section{$\underline{\underline{\text { Ismael Arruda Nazário da Silva }}}$}

1 Professor Doutor da Universidade do Estado do Rio Grande do Norte, UERN, ca_ponte@yahoo.com.br.

2 Mestrando em Texto Literário, Crítica e Cultura pela Universidade do Estado do Rio Grande do Norte, UERN,will_dublin@outlook.com. 
O legendário de Tolkien, como é chamado o conjunto das obras de ficção desse autor, apresenta um tipo especial de personagem denominado hobbit. Essas criaturas apareceram pela primeira vez no meio literário no livro O Hobbit, lançado em 1937, na Inglaterra. Por ter sido um sucesso de venda, os editores do livro pediram a Tolkien que escrevesse uma sequência para a narrativa em que falasse mais sobre a vida dos pequenos, e esse o fez. Assim nasceu $O$ Senhor dos Anéis (1954-1955), considerada a obra-prima do autor.

Essas duas obras são as principais fontes de informação de que o leitor dispõe para compreender o modo de vida dos hobbits, como organização social, política, economia, costumes etc. Existem ainda outras obras póstumas que tratam desses seres, como $O$ Silmarillion (1977), Os Contos Inacabados (1980), e The Peoples of Midle-Earth (1996). No entanto, informações sobre os pequenos estão presentes nas duas obras principais publicadas por ele em vida, às quais nos ateremos neste ensaio.

Objetivamos, dessa forma, investigar o modo de vida dos hobbits no legendário de Tolkien, tendo como fontes $O$ Senhor dos Anéis; especificamente, a Sociedade do Anel, e $O$ Hobbit, relacionando esse modo de vida com o feudal, em vigor na da Idade Média há mais de mil anos, conforme Ginzburg (2010). Analisaremos a forma como as personagens hobbits vivem em Eriador, intercalando esse estudo com a concepção marxista de que a obra literária é fruto de um processo histórico e que ela reflete (conceito de reflexo), de uma forma ou de outra, momentos históricos reais, por mais fantásticas que sejam as histórias narradas.

O materialismo histórico foi desenvolvido por Marx e aponta que a literatura e a arte, de modo geral, resultam de processos históricos complexos, manifestando-se de modo distinto em diferentes momentos, de forma que é possível perceber um tipo de reflexo da sociedade, suas características, por exemplo, nas obras de arte. Acerca disso, Lukács (2010) aponta:

A gênese e o desenvolvimento da literatura são parte do processo histórico geral da sociedade. A essência e o valor estético das obras literárias, bem como a influência exercida por elas, constituem parte daquele processo social e unitário através do qual o homem se apropria do mundo através da consciência. [...] a estética marxista e a história marxista da literatura e da arte fazem parte do materialismo histórico [...] (LUKÁCS, 2010, p. 13). 
Segundo o autor, somente a partir do materialismo histórico é possível compreender a origem da arte, em especial, da literatura, e suas transformações no decurso do tempo. $\mathrm{O}$ autor ainda afirma que a base econômica é a chave, ou princípio diretor, do desenvolvimento histórico das sociedades, passadas e presentes, da qual a arte emerge como fruto, descrevendo e/ou criticando o sistema estabelecido (LUKÁCS, 2010). Em outras palavras, o desenvolvimento político, jurídico, filosófico, religioso, literário, artístico etc., de uma sociedade está fundado no desenvolvimento econômico e deste é dependente. Desse modo, a economia de uma sociedade torna-se não a única causa ativa, mas o estopim de um jogo de ações e reações que acaba por impor-se na dinâmica da vida.

Em se tratando do conceito de reflexo, este não é de todo novo no campo da arte, como aponta Lukács (2010). A ideia da criação artística como imitação, e portanto, reflexo da realidade, já figurava na Poética de Aristóteles há mais de dois mil anos, revelando a preocupação que os filósofos já demonstravam em relação ao produzir artístico. Nesse sentido, a teoria do reflexo não traz nada de novo para a estética marxista e tampouco Marx será o último teórico a tratar da obra de arte como forma de apropriação do real e da sua dinâmica histórica, com suas facetas econômica e social.

A estética marxista também não somente toma a realidade como matriz para criação de um objeto estético, mas, acima de tudo, combate todo tipo de naturalismo do real, e qualquer tendência a simples reprodução do mundo exterior. Assim, Lukács escreve:

\footnotetext{
[...] a concepção marxista do realismo nada tem a ver com a cópia fotográfica da vida cotidiana. A estética marxista se limita a desejar que a essência individualizada pelo escritor não venha representada de maneira abstrata e, sim, como essência organicamente inserida no quadro da fermentação dos fenômenos a partir dos quais ela nasce. Não é absolutamente necessário que o fenômeno artisticamente figurado seja atingido como fenômeno da vida cotidiana e nem mesmo como fenômeno da vida real em geral. Isso significa que até mesmo o mais extravagante jogo da fantasia poética e as mais fantásticas representações dos fenômenos são plenamente conciliáveis com a concepção marxista do realismo (LUKÁCS, 2010, p. 28).
}

A mera reprodução da realidade de modo fotográfico e mecânico pelo autor não ape- 
tece à estética marxista, como visto acima, mas procura fundar a ideia criadora do autor nos fenômenos da vida real. Nessa perspectiva, obras de cunho fantástico e maravilhoso também podem veicular a essência dos fatos históricos dentro de suas próprias características de gênero. Como está apontado acima, é plenamente possível conciliar a concepção marxista do realismo com as produções fantásticas e maravilhosas, como as de Tolkien, aqui apresentadas na forma de $O$ Hobbit e $O$ Senhor dos Anéis, e extrair o princípio que as assenta como obras fundamentadas na realidade.

Isso nos leva à discussão acerca da essência e do fenômeno na estética marxista, abordados por Lukács (2010). Segundo o autor, o marxismo não contrapõe a essência ao fenômeno, mas procura a essência dentro do fenômeno, e analisa a relação do fenômeno na essência. A busca da essência da realidade numa obra artística constitui um processo de aproximação do real, que apresenta-se como gradual, visto que a essência da realidade é sempre uma parte da qual inclusive também fazem parte os fenômeno superficiais. Só ao vislumbrarmos essas considerações, notamos como é complicado extrair a essência do real, do mundo dos fatos, ou dos fenômenos, para usar a terminologia marxista, e sintetizá-la numa criação artística, que se propõe a ser o reflexo da realidade.

Nesse processo de recriação do real numa obra de cunho artístico, nos deparamos com a percepção do autor acerca dos fatos vinculados por ele e na concepção de uma objetividade marxista. É necessário dizer que a estética de Marx não se opõe à ideia da subjetividade no campo da arte; pelo contrário, ele coaduna e afirma ser possível a união dos dois, objetividade e subjetividade, numa obra de reflexão. É a união entre essência do real e percepção pessoal do artista na obra. A essa percepção pessoal, que ele irá defender, chamamos de tese. E esta "[...] é uma tendência política ou social do artista que ele quer demonstrar, defender e ilustrar com a sua própria obra de arte.” (LUKÁCS, 2010, p. 30).

Agora, em se tratando do legendário de Tolkien, composto por obras de caráter maravilhoso, observamos que os hobbits possuem organização social, política e economia próprias, semelhantes às práticas europeias mediáveis. No entanto, antes de discutirmos esse fato, faz-se necessário falarmos um pouco das características das personagens criadas pelo autor britânico. Os hobbits são criaturas maravilhosas desenvolvidas por Tolkien para o universo da Terra-média, lugar imaginário, verossímil norte da Europa, como salienta Lopez (2004), 
povoado por diversas criaturas folclóricas, como elfos, anões e dragões, para citar alguns. No prólogo de O Senhor dos Anéis, Tolkien (2002-b) os descreve:

Eles são (ou eram) um povo pequeno, com cerca de metade da nossa altura, e menores que os anões barbados. Os hobbits não têm barba. Não possuem nenhum ou quase nenhum poder mágico, com exceção daquele tipo corriqueiro de mágica que os ajuda a desaparecer silenciosa e rapidamente quando pessoas grandes e estúpidas como vocês e eu se aproximam de modo desajeitado, fazendo barulho como um bando de elefantes, que eles podem ouvir a mais de uma milha de distância. Eles têm tendência a serem gordos no abdome; vestem-se com cores vivas (principalmente verde e amarelo), não usam sapatos porque seus pés têm uma sola natural semelhante a couro, e também pelos espessos e castanhos parecidos com os cabelos da cabeça (que são encaracolados); têm dedos morenos, longos e ágeis, rostos amigáveis, e dão gargalhadas profundas e deliciosas (especialmente depois de jantarem, o que fazem duas vezes por dia, quando bebem) (TOLKIEN, 2002-a, p. 2).

A citação acima aponta um pouco de como são os hobbits e do que gostam de fazer. Ela consta no início da narrativa $O$ Hobbit. A mesma descrição aparece no prólogo de $O$ Senhor dos Anéis, embora maior e com mais detalhes. Tolkien os caracteriza como um povo alegre que não possui nenhum poder excepcional, ou mágica, exceto fugir rapidamente quando percebem ameaça externa, ou de estranhos. Não são barbados, como anões. Tampouco altos. Eles são bastante pequenos, menores que os anões. São seres muito conectados ao ambiente onde vivem e não gostam de aventuras.

Tolkien refere-se a eles como uma linhagem dos homens, mais próximos desses do que dos anões e elfos. Os hobbits estão entre os filhos mais jovens de Eru Ilúvatar, o Deus maior da Terra-média, e são o resultado do mesmo ato de criação que os homens, como consta em $O$ Silmarillion (2011). Gostavam de cores vivas como o amarelo e o verde, e quase nunca usavam sapatos. Seus rostos eram simpáticos e largos. Gostavam de beber e comer, eram hospitaleiros e gostavam de festas. Os hobbits se instalaram em Eriador após migrarem, vindos do leste, e lá se fixaram, criando o Condado. Foi lá que passaram o resto das suas vidas. Essas pequenas criaturas apropriaram-se do espaço físico e organizaram-se conforme suas necessidades. 
Em $O$ Hobbit, Tolkien escreve uma história para crianças, no formato de um conto de fadas, em que um hobbit sai de casa para desbravar o mundo, juntamente com doze anões e um mago. Durante a aventura, muitas coisas acontecem que permitem ao leitor conhecer a vida dessas pequenas criaturas, principalmente através de Bilbo Bolseiro (em O Hobbit) e de Frodo e Sam (em O Senhor dos Anéis).

Na narrativa de $O$ Hobbit, logo no início, no primeiro parágrafo, notamos nitidamente uma alusão à forma como os pequenos vivem o dia a dia no Condado. Conforme Tolkien, "numa toca no chão vivia um hobbit. Não uma toca desagradável, suja e úmida, cheia de restos de minhocas e com cheiro de lodo; tampouco uma toca seca, vazia e arenosa, sem nada em que sentar ou o que comer: era a toca de um hobbit, e isto quer dizer conforto" (TOLKIEN, 2002-a, p. 1). Eles moram em tocas no chão, mas essas tocas são confortáveis. Não são apenas buracos cheios de minhocas e terra. Muitas das famílias dos hobbits são abastadas e gostam de limpeza.

No prólogo de O Senhor dos Anéis, A Sociedade do Anel, (2002-b), Tolkien informa que originalmente todos os hobbits moravam em tocas, mas, com o tempo, muitos deles passaram a construir moradias na superfície. No Condado, na época de Bilbo, apenas os mais ricos ainda cultivaram o antigo hábito de morar numa toca no chão, ou os mais pobres. A diferença era que as tocas dos mais ricos eram versões luxuosas das escavações, e a dos pobres, meros buracos com uma ou nenhuma janela. Tolkien não informa como os hobbits abastados conseguiram sua riqueza, nem como os pobres chegaram a essa situação.

$\mathrm{Na}$ verdade, o autor britânico pouco escreveu sobre a economia dos hobbits e suas classes sociais. O que temos aos ler os livros são somente vislumbres de uma sociedade agrária, ajustada à terra, à semelhança do paganismo nos primeiros séculos da Idade Média, que conviveu paralelo ao cristianismo na zona rural da Europa (Ginzburg, 2010). Nem espiritualidade vislumbramos, o que pode indicar uma fé, de fato, baseada na terra e nos seus ciclos. Embora saibamos que $O$ Silmarillion reporta o início do mundo e a criação dos povos, e que os homens e elfos saibam dos deuses, não percebemos culto aos Valar e nem a Eru Ilúvatar na sociedade dos hobbits.

Acerca da economia, como apontado, notamos em algumas passagens que os hobbits usavam algum tipo de moeda. No trecho seguinte, retirado da narrativa de $O$ Hobbit, podemos 
perceber algo nesse sentido, quando a estalagem do Dragão Verde é mencionada: "Julgando desnecessário perturbar seu precioso repouso, partimos na frente para fazer os preparativos necessários, e estaremos no aguardo de sua respeitável pessoa na Estalagem Dragão Verde, em Beirágua, às onze horas da manhã em ponto.” (TOLKIEN, 2002 -a, p. 28). Sendo a estalagem um local onde pessoas vão para dormir, comer e beber, é natural pensar que o processo de acomodação de uma pessoa requer o pagamento de algo, e, muito provavelmente, em moedas.

O trecho a seguir também nos permite visualizar um pouco dessa face econômica: "Primeiro tinham passado através das terras dos hobbits, uma ampla e respeitável região, habitada por gente decente, com boas estradas, uma estalagem ou duas, e, de vez em quando, um anão ou um fazendeiro viajando a negócios." (TOLKIEN, 2002-a, p. 30). A passagem discorre sobre a aventura de Bilbo, quando este e a companhia de Thorin abandonam as terras conhecidas e adentram lugares desconhecidos para eles. Uma das palavras que se destacam nesse trecho é "negócios". Não fica claro de que tipo eram, mas muito provavelmente a venda de algo ou mesmo a troca de produtos, conhecida como escambo, que acontecia muito frequentemente nas feiras da Idade Média.

Outra palavra que se destaca é "fazendeiro" na citação anterior. Tolkien escreveu, no prólogo de $O$ Senhor dos Anéis, que os hobbits “[...] amavam a paz e a tranquilidade de uma boa terra lavrada: uma região campestre bem organizada e bem cultivada era seu refúgio favorito". Dá para inferirmos que os hobbits eram fazendeiros e agricultores dedicados. E que muito provavelmente realizavam a troca ou venda dos produtos entre si e entre regiões. Podemos dizer que o trabalho é de estrutura familiar, como imperava na Alta Idade Média, após a queda o Império Romano. Em suma, o que percebemos é uma sociedade agrária altamente ruralizada com trabalho familiar, para subsistência ou comércio.

A Idade Média, em seu início, foi caracterizada pela ruralização e um comércio muito pouco significativo, conforme sugere Ginzburg (2010). A aldeia era praticamente autossuficiente, produzia para si, e a vida econômica acontecia sem muita utilização de capital. Naquele período, a palavra "mercado" denominava o local, o espaço físico, onde, semanalmente, realizava-se a troca de produtos excedentes. A sociedade dos hobbits muito se assemelha, nesse quesito, àquela sociedade autossuficiente. Tolkien muito provavelmente apropriou-se da ideia não somente para criar a forma de vida dos pequenos, mas também para dar vida ao seu uni- 
verso que é eminentemente medieval, como se percebe pelos elementos típicos de narrativas maravilhosas contidos em suas histórias, como reis, rainhas, elfos, magos, etc.

É interessante apontarmos que a nova estrutura da sociedade conhecida como Idade Média, depois da queda do império romano, marcou uma organização de poderes fragmentados, sem um Estado que os unificasse, predominantemente agropastoril. A Idade Média foi um período que durou aproximadamente mil anos. Existiam inúmeros reinos, o que tornava o poder descentralizado. Ou seja, não havia uma única figura central em torno da qual o poder político fosse organizado, concentrado e exercido. Existiam, na realidade, variados reinos, dentro dos quais figuras de poder, ou reis, governavam.

No que concerne aos hobbits, sua organização política era simples, mas eles possuíam seus próprios líderes. Isso em momentos bem recentes de sua história; pois, outrora, havia um rei e os hobbits eram seus súditos nominais.

\footnotetext{
Enquanto ainda havia um rei, eram seus súditos nominais; mas na verdade eram governados por seus próprios líderes e não se misturavam de modo algum com os acontecimentos do mundo lá fora. Na última batalha em Fornost contra o Rei dos Bruxos de Angmar, enviaram alguns arqueiros para ajudar o rei, ou pelo menos assim afirmavam, embora nenhuma história dos homens confirme a informação. Mas com aquela guerra do Reinado do Norte acabou; e então os hobbits tomaram a terra para si próprios, e escolheram entre seus próprios chefes um Thain para ocupar o lugar de autoridade do rei que havia partido. Ali, por mil anos, tiveram poucos problemas com guerra, e prosperaram e se multiplicaram depois da Peste Negra (R.C. 37) até o desastre do Inverno Longo e a penúria que o seguiu. [...] A terra era boa, e, embora já estivesse abandonada por muito tempo quando lá chegaram, fora bem cultivada antes, e ali o rei possuíra muitas fazendas, plantações de milho, vinhedos e bosques (TOLKIEN, 2002-b, p. 7).
}

A história dos hobbits é um tanto fragmentada e Tolkien não a reconstruiu em sua totalidade. As informações estão dispersas em pedaços que podem ser achados, especialmente, em Os Contos Inacabados, O Silmarillion e em O Senhor dos Anéis. Pelas citações, é possível notar que a todo momento Tolkien nos apresenta elementos que fazem referência ao universo 
medieval. Na citação acima, por exemplo, além de termos os reis como referências, temos também a peste negra, doença que matou $1 / 3$ da população europeia no século XIV, como salienta Ginzburg (2010), sendo uma das maiores epidemias da história.

A terra dos hobbits se estendia por 120 milhas desde as Colinas Distantes até a Ponta do Brandevin, e por 150 milhas doa pântanos do norte até os charcos do sul. Eles o chamaram de Condado, e o transformaram em um distrito de negócios bem-organizado. O condado era dividido em quatro partes (ou Quartas), cada uma seguindo um ponto cardeal: a Quarta Norte, a Sul, a Leste e a Oeste, que se dividiam, por seu turno, em vários povoados, que levavam os nomes das famílias mais importantes da região, segundo Tolkien (2002-b). No entanto, pelo material que Tolkien deixou escrito, essa organização foi se diluindo com o tempo e, na época da aventura de Frodo, o Condado mal possuía um governo. Como o autor afirmou, as famílias, na maior parte das vezes, cuidavam de seus próprios negócios, que envolviam, sem exagero, cultivar a comida e comê-la.

O Condado possuía somente um cargo oficial naquela época ,que era o de Prefeito de Grã Cava e do Condado, eleito a cada sete anos na Feira Livre nas Colinas Brancas no Solstício de Verão. O prefeito não possuía muitas atribuições, apenas o de gerenciar as mensagens postais e a polícia, além de presidir banquetes, como podemos notar a seguir:

\footnotetext{
Como Prefeito, seu quase único dever era presidir banquetes, oferecidos nos feriados do Condado, que ocorriam a intervalos frequentes. Mas os cargos de Agente Postal e de Primeiro Condestável foram acrescentados ao de Prefeito, de modo que este gerenciava tanto o Serviço de Mensagens como a Patrulha. Esses eram os únicos funcionários do Condado, e os Mensageiros eram os mais numerosos e os mais ocupados dos dois (TOLKIEN, 2002-b, p. 14).
}

Os condestáveis compunham a polícia dos hobbits. Não possuíam uniformes, pois não conheciam esse tipo de coisa, usavam apenas uma pena em seus chapéus. Tolkien escreve que eles pareciam mais com pastores do que com membros da polícia. Havia somente doze deles em todo o Condado, três condestáveis em cada Quarta. No entanto, dado o número dessas pessoas, as regiões ficavam, certamente, em sua maioria, sem o serviço previsto para ser posto em prática. Os hobbits cultivavam tanto a paz e a tranquilidade, que esse tipo de trabalho devia ser dispensável na sociedade dos pequenos. 
Como pode se perceber, a sociedade dos hobbits criada por Tolkien é uma sociedade de caráter medieval e bem simples, composta de pessoas que praticam a agricultura e vivem muito ajustadas ao ambiente. Sua economia é baseada na mão de obra familiar, com troca ou venda de produtos excedentes em feiras. O território onde moram é dividido em Quartas e é administrado por um prefeito. No entanto, pelo que compreendemos, este é mais um cargo simbólico, uma vez que são as famílias que organizam a vida na região. Possuem policiais, mas também possuem um caráter simbólico, pois o número reduzido deles diminui a devida importância da atividade.

A criação artística, desse modo, apresenta-se como um reflexo da realidade na obra de Tolkien, revelando características verossímeis que permitem o estudo de uma dada sociedade: sua organização social, sua política, sua economia, por exemplo, pelo viés literário. Mas a obra artística vai muito além da mera reprodução do real. Ela carrega em si a visão particular do seu criador, que permite a liberdade do leitor ao compreendê-la na forma de múltiplos pontos de vistas, ou teses, que podem ser inferidos no momento da apreciação estética, ou da leitura, no caso da estética literária. 


\section{Referências}

GINZBURG, Carlo. O queijo e os vermes. São Paulo: Companhia das Letras, 2010.

LOPEZ, R. S. O senhor dos anéis e Tolkien: o poder mágico da palavra. São Paulo: Devir: Arte e Ciência, 2004.

LUKÁCS, Georg. Introdução aos escritos estéticos de Marx e Engels. In: Cultura, Arte e Literatura: textos escolhidos. Tradução de José Paulo Netto e Miguel Makoto Cavalcante Yoshida. 1. ed. São Paulo: Expressão Popular, 2010, p. 11-37.

TOLKIEN, J.R.R. O Hobbit. Tradução de Lenita Maria Rímoli Esteves e Almiro Pisetta. São Paulo: Martins Fontes, 2002-a.

O Senhor dos Anéis: A sociedade do anel. Tradução de Lenita Maria Rímoli Esteves e Almiro Pisetta. São Paulo: Martins Fontes, 2002-b.

O Silmarillion. Tradução de Waldéa Barcelos. São Paulo: Martins Fontes, 2011. 